\title{
Can ROMA algorithm stratify ovarian tumor patients better when being based on specific age ranges instead of the premenopausal and postmenopausal status?
}

\author{
Anita Chudecka-Glaz ${ }^{1}$ Aneta Cymbaluk-Płoska ${ }^{1}$. Jolanta Jastrzębska ${ }^{2}$. \\ Janusz Menkiszak ${ }^{1}$
}

Received: 22 November 2015 / Accepted: 21 December 2015/Published online: 11 January 2016

(C) The Author(s) 2016. This article is published with open access at Springerlink.com

\begin{abstract}
After several years of research, HE4 was found to be characterized by slightly worse sensitivity but significantly higher specificity as compared with CA125. Further studies led to the diagnostic potential of both markers (CA125 and HE4) being combined in a single risk of malignancy algorithm (ROMA) algorithm. The objective of this study was to assess the diagnostic capabilities of the ROMA algorithm using age ranges instead of dichotomization of patients according to the pre- and postmenopausal status. A total of 413 female patients were included in the study, including 162 premenopausal and 251 postmenopausal women. Calculation of the final ROMA values was achieved by means of stepwise reduction of coefficients in the proposed formula of: $\% \mathrm{ROMA}=\exp (\mathrm{PI}) /[1-$ $\left.\exp (\mathrm{PI})]^{*} 100\right)$ and $\mathrm{PI}=\mathrm{A}+\mathrm{W}(\mathrm{HE} 4)^{*} \ln (\mathrm{HE} 4)+\mathrm{W}(\mathrm{CA} 125)^{*} \ln$ (CA125) and the arrangement of values with consideration to the age group, HE4 level, differentiation of modification, and directional coefficients as well as determination of individual deviations affecting the widening of the median. The cutoff value of modified algorithm ROMA P for the entire study population was calculated from receiver operating characteristic (ROC) curve and DeLong method at the levels of $23.5 \%$. Marked higher sensitivity and negative predictive value (NPV) values are observed for the standard ROMA algorithm while higher specificity and positive predictive value (PPV) values are observed for the modified algorithm ROMA P. The
\end{abstract}

Anita Chudecka-Głaz anitagl@poczta.onet.pl

1 Department of Gynecological Surgery and Gynecological Oncology of Adults and Adolescents, Pomeranian Medical University, Al. Powstańców Wielkopolskich 72, 70-111 Szczecin, Poland

2 High School Number 2 in Szczecin, Szczecin, Poland proposed age-related modification of algorithm calculation does not require the patients being dichotomized according to their pre- or postmenopausal status, and satisfactory diagnostic values may be obtained using a single cutoff point for the entire population.

Keywords HE4 · CA125 - ROMA algorithm · Ovarian cancer $\cdot$ Diagnosis

\section{Introduction}

Ovarian cancer is responsible for the largest number of deaths due to gynecological cancers in European and North American women. Worldwide, it is second only to cervical cancer. Annual incidence of ovarian cancer is estimated at more than 200,000 cases while the mortality is estimated at over 150,000 of deaths [1]. Currently, we have no sufficient capabilities to perform ovarian cancer screening examinations in the entire population of women. The partial screening program includes high-risk patients with BRCA 1 or BRCA 2 gene mutations [2]. Therefore, the main stress is placed on the possibilities of earlier diagnostics and identification of ovarian cancer at earlier stages of the disease. Clinical staging remains one of the most important prognostic factors that impact the survival parameters in patients [3]. The first marker used in routine diagnostics of ovarian cancer was the antigen CA125, widely used to date [4]. In 2003, Hellstrom et al. [5] were the first to report the potential use of HE4 as a marker in the diagnostics of ovarian cancer. After several years of research, HE4 was found to be characterized by slightly worse sensitivity but significantly higher specificity as compared with CA125 [6-11]. Further studies led to the diagnostic potential of both markers (CA125 and HE4) being combined in a single risk of malignancy algorithm (ROMA) [12-16]. According to numerous 
studies conducted to date, ROMA appears to be one of the best methods for stratification of ovarian tumor patients into groups of high vs. low risk of ovarian cancer. The algorithm is objective, easy to perform, inexpensive, and characterized by appropriate sensitivity and specificity $[12,13]$. However, the search for methods for achieving better results in terms of the algorithm's sensitivity and specificity is ongoing $[17,18]$.

The objective of this study was to assess the diagnostic capabilities of the ROMA algorithm using age ranges instead of dichotomization of patients according to the pre- and postmenopausal status.

\section{Materials and methods}

\section{Patients}

A total of 413 female patients were included in the study, including 162 premenopausal and 251 postmenopausal women. Patients were diagnosed and treated at the Department of Gynecological Surgery and Gynecological Oncology Adults and Adolescents in Szczecin, Poland, between 2011 and 2015. Qualified for the study were the consecutive patients who attend the hospital presenting with ovarian tumor, ovarian cyst, or ascites (suspected ovarian cancer). After informed consent was obtained, blood samples were collected simultaneously and serum levels of HE4 and CA125 were determined on current basis without freezing at the hospital's Central Laboratory. All the samples were taken before diagnosis, not in the follow-up period. Both markers are routinely determined in all patients reporting to our clinic with adnexal lesions. ROMA algorithm analyses based on specific age groups were performed in a retrospective manner after an appropriate formula was determined. In the clinical decision-making process, each marker was analyzed separately. After histopathological examination results were obtained, patients were finally qualified into one of the two groups:

\section{A. Patients with ovarian cancer \\ B. Patients with benign adnexal lesions}

Patients with history of chronic renal diseases, history of chronic lung diseases, metastatic ovarian tumors, ongoing treatment of other cancers, or presenting with elevated creatinine levels were not qualified to the study. A detailed division of patients in both groups is presented in Table 1.

Median values and ranges were determined for both groups and all respective subgroups, with appropriate comparisons being made with respect to the levels of HE4 and CA125, ROMA algorithm calculated in the standard manner (ROMA) as well as the modified ROMA algorithm (ROMA P). Sensitivity, specificity, as well as positive and negative predictive values of CA125 and HE4 were determined for the standard and the modified algorithm. Additionally, diagnostic usefulness of each marker was determined using ROC-AUC.

Calculation of the final ROMA values was achieved by means of stepwise reduction of coefficients in the proposed formula of:

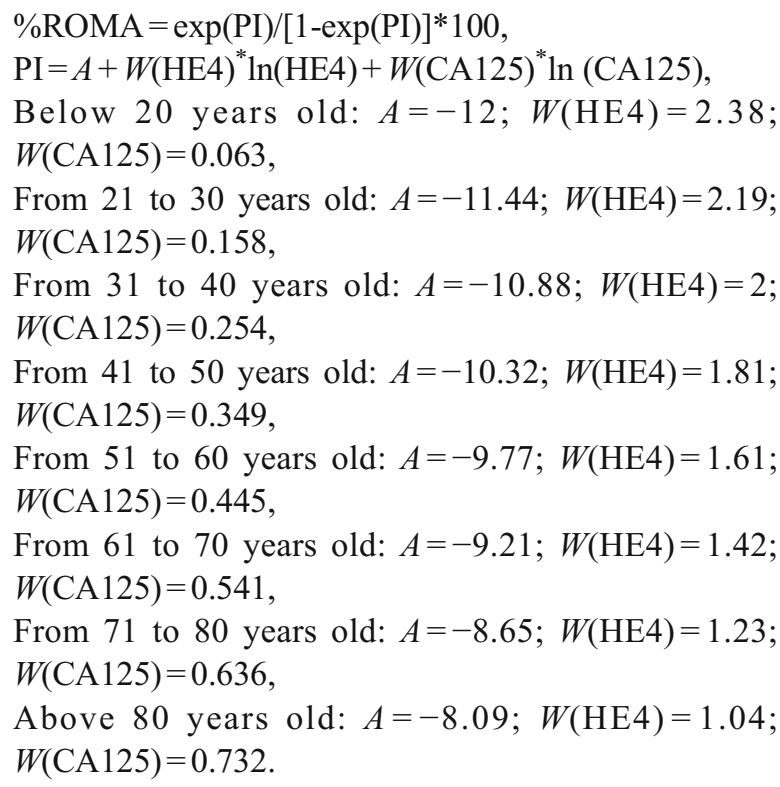

In the calculation, we used also the arrangement of values with consideration to the age group, HE4 level, differentiation of modification and directional coefficients, as well as determination of individual deviations affecting the widening of the median.

\section{Laboratory methods}

The HE4 serum levels of the marker were determined using the Roche Elecsys ${ }^{\circledR}$ assay on a Cobas e601 apparatus. This is a one-step sandwich electro-chemiluminescence immunoassay (ECLIA) for quantitative determination of human epididymal protein 4 . The detection range for HE4 was $15-1500 \mathrm{pmol} / \mathrm{l}$; in case of values exceeding $1500 \mathrm{pmol} / \mathrm{l}$, the samples were diluted in a 1:20 ratio using Elecsys Diluent.

The CA125 serum levels of the marker were determined using the ARCHITECT CA125 II assay on an ARCHITECT 2200SR System. This is a two-step immunoassay to determine the presence of CA125 antigen using Chemiluminescent Microparticle Immunoassay (CMIA) technology.

CA125 and HE4 assays were carried out according to manufacturers' instructions, with appropriate controls testing within the normal ranges. The detection range for CA125 was $1-35 \mathrm{U} / \mathrm{ml}$.

\section{Statistical analysis}

Descriptive characteristics of the examined population of patients were prepared, including the minimum, maximum, mean, and median values. Also, the scatter diagrams of the empirical values of markers were plotted for individual study groups. The mean/ 
Table 1 Patients characteristics

\begin{tabular}{|c|c|c|}
\hline & $\begin{array}{l}\text { Ovarian cancers } \\
n(\%) \\
162\end{array}$ & $\begin{array}{l}\text { Benign diseases } \\
n(\%) \\
251\end{array}$ \\
\hline \multicolumn{3}{|l|}{ Age } \\
\hline Median & $59.7(24-90)$ & $35(18-88)$ \\
\hline \multicolumn{3}{|l|}{ Range } \\
\hline \multicolumn{3}{|l|}{ Hormonal status } \\
\hline Premenopausal & $38(23.5)$ & $214(85.3)$ \\
\hline Postmenopausal & $124(76.5)$ & $37(14.7)$ \\
\hline \multicolumn{3}{|l|}{ Age interval } \\
\hline W1 ( <20 YO) & - & $38(15.1)$ \\
\hline W2 (21-30) & $3(1.9)$ & $55(21.9)$ \\
\hline W3 (31-40) & $7(4.3)$ & $73(29.1)$ \\
\hline W4 (41-50) & $28(17.3)$ & $48(19.1)$ \\
\hline W5 (51-60) & $47(29)$ & $22(8.8)$ \\
\hline W6 (61-70) & $43(26.5)$ & $10(4)$ \\
\hline W7 (71-80) & $25(15.4)$ & $4(1.6)$ \\
\hline W8 (>81) & $9(5.6)$ & $1(0.4)$ \\
\hline Ovarian cancer histopathology & & NA \\
\hline Serous & $132(81.5)$ & NA \\
\hline Mucinous & $9(5.6)$ & NA \\
\hline Clear cell & $8(4.9)$ & NA \\
\hline Endometrioid & $13(8)$ & NA \\
\hline Oarian cancer FIGO stage & & NA \\
\hline Stages I and II & $54(33.3)$ & NA \\
\hline Stages III and IV & $105(64.7)$ & NA \\
\hline Ovarian cancer grade & & NA \\
\hline Grade 1 & $34(21)$ & NA \\
\hline Grade 2 & $54(33.3)$ & NA \\
\hline Grade 3 & $74(45.7)$ & NA \\
\hline \multicolumn{3}{|l|}{ Benign tumor histopathology } \\
\hline Endometriosis & NA & $120(47.8)$ \\
\hline Teratoma & NA & $43(17.1)$ \\
\hline Follicular cysts & NA & $33(13.1)$ \\
\hline Paraovarian cysts & NA & $26(10.4)$ \\
\hline Hemorrhagic cysts & NA & $28(11.6)$ \\
\hline
\end{tabular}

median values in individual groups and subgroups were compared using the nonparametric Mann-Whitney's $U$ test.

The contingency table was used in the assessment of diagnostic usefulness of CA125 and HE4 assays and ROMA values and subsequent calculation of the following parameters:

$$
\begin{aligned}
& \text { Sensitivity }=\mathrm{TP} / \mathrm{TP}+\mathrm{FN} \\
& \text { Specificity }=\mathrm{TN} / \mathrm{FP}+\mathrm{TN} \\
& \text { Positive predictive value }(\mathrm{PPV})=\mathrm{TP} / \mathrm{TP}+\mathrm{FP} \\
& \text { Negative predictive value }(\mathrm{NPV})=\mathrm{TN} / \mathrm{FN}+\mathrm{TN}
\end{aligned}
$$

The diagnostic performance was studied using receiver operating characteristic (ROC) curves based on continuous variables.
HE4, CA125, and ROMA represented diagnostic variables acting as stimulants which increase the probability of ovarian cancer proportionally to their rising value. The area under curve (AUC), standard error ( $\left.\mathrm{SE}_{\mathrm{AUC}}\right)$, and confidence interval $\left(\mathrm{CI}_{\mathrm{AUC}}\right)$ values for AUC were calculated according to the nonparametric method of DeLong. We used this method to compare AUCs considering the fact that measurements of HE4, CA125, and ROMA were done for the same objects (groups of patients). The level of significance was taken as $p<0.05$.

\section{Results}

\section{Patient, biomarker, and algorithm baseline characteristics}

Detailed characteristics of patients are presented in Table 1. The analysis included a total of 162 patients with ovarian cancer. As much as $81.5 \%$ of these cancers were serous and $64.7 \%$ of serous was of a high clinical stage. The group of benign gynecological disorders consisted of 251 patients, $47.8 \%$ of those being diagnosed with endometriosis. Also presented in Table 1 is the distribution of patients into individual age groups used for modification of the ROMA algorithm.

Medians and ranges or marker levels as well as values obtained using the standard and the modified ROMA algorithm are presented in Table 2. Comparative analysis between the values from the standard and the modified algorithm revealed no statistically significant differences within the analyzed groups and subgroups. The only clearly evident difference was related to benign disorders being pooled regardless of histopathological type, where the values obtained using the modified algorithm were significantly higher (6.7 vs. $8.29 \%$, $p=0.0001)$.

\section{ROC curve analysis}

ROC curves were determined for CA125, HE4, ROMA, and ROMA $P$ in the entire study population, in the premenopausal group, in the postmenopausal group, as well as in the groups of high- and low-stage ovarian tumors (Table 3; Fig. 1). In every case, each of the markers as well as both algorithms met the criteria of good diagnostic tests with AUC values calculated for ROC curves being above 0.5 . The modified algorithm ROMA P is significantly better than CA125 in the advanced cancer group (AUC $=0.994$ vs. 0.969 ) and better than HE4 in all cases except for the advanced cancer group. When comparing the standard ROMA algorithm and the modified ROMA P algorithm, superiority of standard algorithm was observed in the group of postmenopausal patients

ROC curves were also determined within the analyzed age ranges (Table 4). Similarly, also in this case, all analyzed parameters met the criteria of very good diagnostic tests in all age groups. There were no significant differences between the 
modified algorithm ROMA P and CA125, HE4, and the standard ROMA algorithm. A trend towards higher AUS values and thus towards a better diagnostic value was observed with the increasing patients' age.

\section{Sensitivity, specificity, PPV, and NPV}

The cutoff value of modified algorithm ROMA P for the entire study population was calculated from receiver operating characteristic (ROC) curve and DeLong method at the levels of $23.5 \%$. The cutoff value of standard algorithm ROMA was calculated based on the same statistical method at the levels of $14.1 \%$ for the premenopausal and $25 \%$ for postmenopausal women. The sensitivity, specificity, positive predictive value and negative predictive value were calculated on the basis of contingency tables, see Table 5. The difference between the compared algorithms is evident. Marked higher sensitivity and NPV values are observed for the standard ROMA algorithm while higher specificity and PPV values are observed for the modified algorithm ROMA P.

\section{Discussion}

In 2008, Moore et al. [12] determined that of all known biomarkers within the panel used for diagnosing ovarian cancer, HE4 was characterized by the highest sensitivity and specificity. Numerous studies demonstrated a significant

Table 2 Serum CA125, HE4, ROMA, and ROMA P levels according to age, histology, FIGO stage, and tumor grade

\begin{tabular}{|c|c|c|c|c|c|c|c|c|c|}
\hline & \multicolumn{2}{|c|}{ CA125 (U/ml) } & \multicolumn{2}{|c|}{ HE4 (pmol/l) } & \multicolumn{2}{|c|}{ ROMA (\%) } & \multicolumn{2}{|c|}{ ROMA P (\%) } & \multirow[t]{2}{*}{ p (ROMA vs. ROMA P) } \\
\hline & Median & Range & Median & Range & Median & Range & Median & Range & \\
\hline Ovarian cancer (all) & 397.5 & $9-7459.1$ & 340.7 & $12-9264$ & 90.3 & $0.5-100$ & 91.46 & $1.33-99.9$ & 0.8641 \\
\hline Serous & 421.1 & $9-7459.1$ & 390.7 & $15-9264$ & 91.9 & $0.5-100$ & 92.5 & $1.3-99.9$ & 0.7963 \\
\hline Mucinous & 58.8 & $11.3-600$ & 69.2 & $15-538$ & 30.1 & $6.2-95.8$ & 27.2 & $1.9-96.1$ & 0.9699 \\
\hline Clear cell & 389.9 & $95.8-1725.5$ & 184.8 & $49.5-849.9$ & 81.5 & $8.1-98.2$ & 73.7 & $15.6-98.3$ & 0.9581 \\
\hline Endometrioid & 00 & $41.5-2996.8$ & 340.7 & $46.1-1235$ & 94.6 & $21-99.3$ & 93.2 & $2.5-99.4$ & 0.9591 \\
\hline FIGO stages I and II & 130.3 & $9-2347$ & 79 & $15-1235$ & 35.3 & $0.5-99.3$ & 33.6 & $1.3-99.3$ & 0.8610 \\
\hline FIGO stages III and IV & 591 & $18-7459.1$ & 593.75 & $20.7-9264$ & 96.8 & $9-100$ & 97.1 & $10.1-99.9$ & 0.6691 \\
\hline Grade 1 & 68.2 & $9-459.7$ & 70.8 & $15-414.3$ & 20.5 & $0.5-93.9$ & 23.1 & $1.3-93.8$ & 0.9087 \\
\hline Grade 2 & 420.1 & $14-7459.1$ & 289.3 & $20.7-9264$ & 88.5 & $8.4-100$ & 88.9 & $10.1-99.9$ & 0.0114 \\
\hline Grade 3 & 535.1 & $11.2-5109.8$ & 569.8 & $20.4-8160$ & 96.7 & $1-100$ & 96.4 & 2.98-99.9 & 0.8963 \\
\hline Benign diseases (all) & 22.5 & $3.2-502.7$ & 46.7 & $17.8-206.5$ & 6.7 & $0.7-87$ & 8.29 & $1.15-85.2$ & 0.0001 \\
\hline Endometriosis & 45.5 & $6.7-377$ & 45.2 & $17.8-86.7$ & 6.6 & $0.7-35.34$ & 9.1 & $1.2-26.16$ & 0.2295 \\
\hline Teratoma tumors & 15.5 & $6.3-51.9$ & 46.6 & $26.3-724$ & 6.48 & $1.65-17.9$ & 6.76 & $1.87-17.6$ & 0.2835 \\
\hline Follicular cysts & 14.5 & $3.2-88$ & 55.3 & $24.2-206.5$ & 8.76 & $1.6-65.7$ & 9.9 & $1.6-67.8$ & 0.4886 \\
\hline Paraovarian cysts & 13.7 & $4.1-52.7$ & 48.6 & $36.4-186.8$ & 7.5 & $3.7-87$ & 7.9 & $3.8-85.2$ & 0.7075 \\
\hline Hemorrhagic cysts & 15.4 & $5.5-274.8$ & 44.3 & $24.8-95.7$ & 5.7 & $1.7-31.6$ & 6.5 & $3.2-30.9$ & 0.6522 \\
\hline \multicolumn{10}{|l|}{ AGE interval } \\
\hline W1 ovarian cancer group & - & - & - & - & - & - & - & - & - \\
\hline W2 ovarian cancer group & 55.2 & $27-135.1$ & 45.4 & $44.1-103.9$ & 6.2 & $6-35$ & 7.5 & $7.1-37.7$ & 0.3827 \\
\hline W3 ovarian cancer group & 403.6 & $98.1-1252$ & 95.4 & $15-464.8$ & 31.5 & $0.5-95.5$ & 43.6 & $1.3-95.6$ & 0.3619 \\
\hline W4 ovarian cancer group & 265.4 & 144638.8 & 92.9 & $15-1500$ & 34.7 & $0.5-99.7$ & 44.7 & $1.3-99.4$ & 0.7743 \\
\hline W5 ovarian cancer group & 500 & $9-5887$ & 439.3 & $12-1655$ & 96.4 & $4.5-99.7$ & 96.3 & $1.9-99.8$ & 0.7883 \\
\hline W6 ovarian cancer group & 233.3 & $9.8-7459.1$ & 334.5 & $22-9264$ & 90.9 & $6-100$ & 91.6 & $5.2-99.9$ & 0.9786 \\
\hline W7 ovarian cancer group & 839 & $21-5659$ & 658.4 & $37-8160$ & 97 & $25-100$ & 97.2 & $23.8-99.9$ & 0.7710 \\
\hline W8 ovarian cancer group & 777.5 & $66.9-3724$ & 871.2 & $85.8-4940$ & 97.7 & $55.1-100$ & 97.9 & $55.1-99.9$ & 1.0000 \\
\hline W1 benign group & 16 & $4.1-274.8$ & 41.5 & $24.2-84.7$ & 6.2 & $1.56-22.1$ & 6.4 & $1.56-22.1$ & 0.9420 \\
\hline W2 benign group & 28.1 & $7.7-377$ & 45.5 & $26.3-80.4$ & 5.4 & $1.65-20.3$ & 6.2 & $1.87-22.7$ & 0.0913 \\
\hline W3 benign group & 32.3 & $7.1-191.5$ & 47.3 & $31.7-86.7$ & 7 & $2.6-24.1$ & 9.2 & $3.2-26.2$ & 0.9529 \\
\hline W4 benign group & 21.6 & $5.5-168.8$ & 44.5 & $17.8-74.2$ & 6 & $0.7-17.6$ & 8.9 & $1.15-21.3$ & 0.0079 \\
\hline W5 benign group & 12.4 & $3.2-82.1$ & 48.5 & $27.5-85.1$ & 6.9 & $1.8-35.3$ & 8.4 & $4.4-23.4$ & 0.6641 \\
\hline W6 benign group & 15.9 & $6.7-79.8$ & 63.8 & $47.1-206.5$ & 14.3 & $6.7-65.7$ & 14.1 & $6.6-67.8$ & 0.6232 \\
\hline W7 benign group & 9.55 & $6.3-52.7$ & 69.5 & $52-186$ & 9.7 & $7.3-87$ & 9.7 & $7.6-85.2$ & 1.0000 \\
\hline
\end{tabular}


Table 3 Values and comparisons of ROC-AUC for ROMA, ROMA P, CA125, and HE4 in studied groups

\begin{tabular}{|c|c|c|c|c|}
\hline \multirow{2}{*}{$\begin{array}{l}\text { Tumor } \\
\text { marker }\end{array}$} & \multirow{2}{*}{$\begin{array}{l}\text { ROC-AUC } \\
(95 \% \mathrm{CI})\end{array}$} & \multicolumn{3}{|c|}{ Comparison of ROC-AUC } \\
\hline & & $\begin{array}{l}\text { ROMA P vs. CA } 125 \\
p \text { value }\end{array}$ & $\begin{array}{l}\text { ROMA P vs. HE4 } \\
p \text { value }\end{array}$ & $\begin{array}{l}\text { ROMA P vs. ROMA } \\
p \text { value }\end{array}$ \\
\hline \multicolumn{5}{|c|}{ All ovarian cancer vs. benign ovarian diseases } \\
\hline $\begin{array}{l}\text { ROMA } \\
\text { ROMA P }\end{array}$ & $\begin{array}{l}0.934 \\
0.923\end{array}$ & \multirow[t]{3}{*}{0.4222} & \multirow[t]{3}{*}{0.0004} & \multirow[t]{3}{*}{0.1411} \\
\hline HE4 & 0.881 & & & \\
\hline CA125 & 0.910 & & & \\
\hline \multicolumn{5}{|c|}{ Advanced ovarian cancers vs. benign ovarian diseases } \\
\hline $\begin{array}{l}\text { ROMA } \\
\text { ROMA P }\end{array}$ & $\begin{array}{l}0.995 \\
0.994\end{array}$ & \multirow[t]{3}{*}{0.0205} & \multirow[t]{3}{*}{0.0778} & \multirow[t]{3}{*}{0.7725} \\
\hline HE4 & 0.982 & & & \\
\hline CA125 & 0.969 & & & \\
\hline \multicolumn{5}{|c|}{ Not-advanced ovarian cancers vs. benign ovarian diseases } \\
\hline $\begin{array}{l}\text { ROMA } \\
\text { ROMA P }\end{array}$ & $\begin{array}{l}0.820 \\
0.794\end{array}$ & \multirow[t]{3}{*}{0.7623} & \multirow[t]{3}{*}{0.0013} & \multirow[t]{3}{*}{0.1531} \\
\hline HE4 & 0.691 & & & \\
\hline CA125 & 0.808 & & & \\
\hline \multicolumn{5}{|c|}{ All ovarian cancers vs. benign ovarian diseases - premenopausal patients } \\
\hline $\begin{array}{l}\text { ROMA } \\
\text { ROMA P }\end{array}$ & $\begin{array}{l}0.812 \\
0.829\end{array}$ & \multirow[t]{3}{*}{0.3393} & \multirow[t]{3}{*}{0.0242} & \multirow[t]{3}{*}{0.2049} \\
\hline HE4 & 0.779 & & & \\
\hline CA125 & 0.876 & & & \\
\hline \multicolumn{5}{|c|}{ All ovarian cancers vs. benign ovarian diseases - postmenopausal patients } \\
\hline $\begin{array}{l}\text { ROMA } \\
\text { ROMA P }\end{array}$ & $\begin{array}{l}0.945 \\
0.935\end{array}$ & \multirow[t]{3}{*}{0.4277} & \multirow[t]{3}{*}{0.0022} & \multirow[t]{3}{*}{0.0495} \\
\hline HE4 & 0.888 & & & \\
\hline CA125 & 0.947 & & & \\
\hline
\end{tabular}

improvement in the sensitivity and specificity of prediction of pathological changes within the adnexes when using CA125 and HE4 together instead of as separate markers [12, 19-22]. The sensitivity of CA125, when analyzed together with HE4, increases from 43 to $76.4 \%$ [12]. Therefore, in 2009, Moore et al. [23] described the first predictive model for estimation of the risk of malignant epithelial ovarian cancer in women with pathological lesions within the pelvic region. In 2011, on the basis of the research of the same authors [24], the Food and Drug Administration approved the algorithm for clinical use. A continuous increase in the number of published studies on the application of ROMA in clinical practice has been observed ever since [25-29]. In 2012, during an experts' meeting in Wiesbaden, the efficacy of ROMA was confirmed. Possibilities for improving the algorithm's diagnostic abilities were also considered by including additional analysis of patients' age, smoking status, renal insufficiency-related conditions, or acute cardiac insufficiency-related conditions [17].

It seems the most important factor affecting HE4 levels and thus the ROMA algorithm values is the age of the patients [3-33]. In the study by Bolstadt et al. [32], conducted in a European population, HE4 level as compared with that in women at the age of 20 was found to be increased by $2 \%$ in women at the age of 30, $9 \%$ in women at the age of $40,20 \%$ in women at the age of $50,37 \%$ in women at the age of $60,63 \%$ in women at the age of 70, and as much as $101 \%$ in women at the age of 80 . The authors suggest that HE4 levels should be analyzed in caution in patients after the age of 70. Moore et al. [31] observed the following HE4 level changes correlated with patients' age: median level was $46.2 \mathrm{pmol} / 1$ before the age of 30 , $43.5 \mathrm{pmol} / \mathrm{L}$ at the age of $30-39,50.5 \mathrm{pmol} / \mathrm{l}$ after the age of 40 and before menopause, $50.7 \mathrm{pmol} / 1$ before the age of 60 and after menopause, $59.8 \mathrm{pmol} / \mathrm{l}$ at the age of $60-69,66.9 \mathrm{pmol} / \mathrm{l}$ at the age of 70-79, and as much as $113.4 \mathrm{pmol} / \mathrm{l}$ after the age of 80. In our study population, HE4 levels were also found to increase with age, albeit to a smaller degree than reported by Bolstad [33] and Moore [31]. In our analysis, the increase in HE4 levels after the age of 60 as compared with the value at the age of below 20 was about $40 \%$. Of course, this may be due to the differences in analytical tests as Bolstad et al. [33] and Moore et al. [31] used laboratory tests from Fujirebio while our study was conducted using laboratory tests from Roche. ROMA values (modified ROMA values) were calculated using stepwise reduction of coefficients while taking into account the different 
Fig. 1 ROC curves of the standard ROMA algorithm and the ROMA P (algorithm calculated in the age ranges)

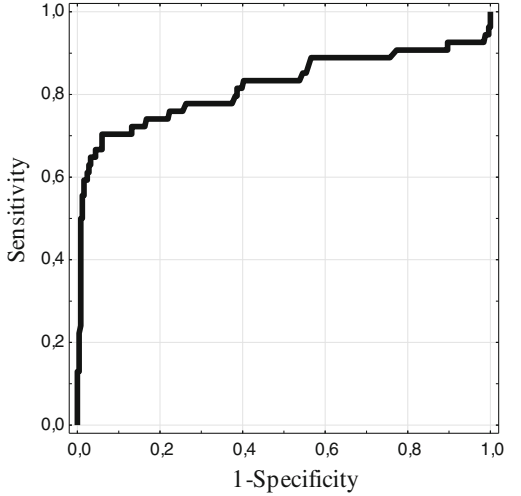

ROMA, not advanced ovarian cancer

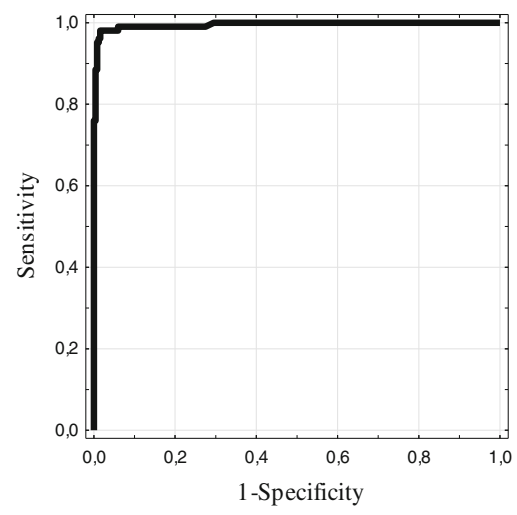

ROMA, advanced ovarian cancer

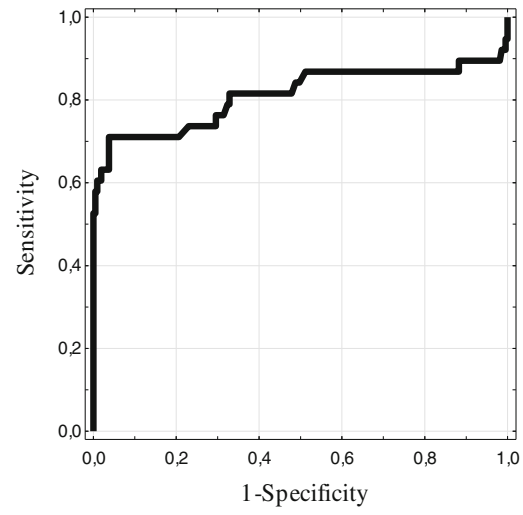

ROMA, premenopausal women

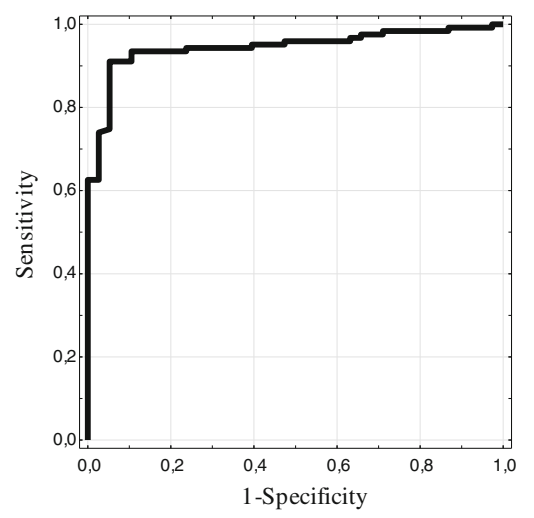

ROMA, postmenopausal women

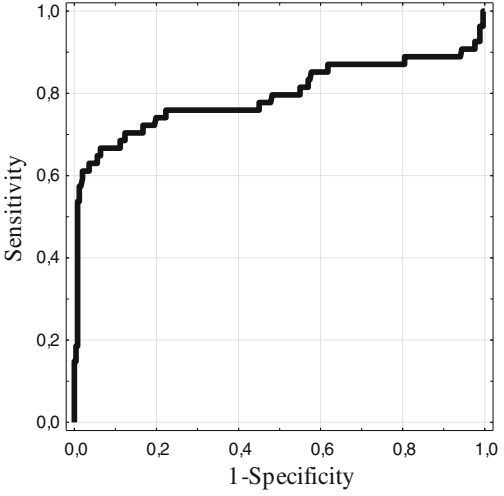

ROMA P, not advanced ovarian cancer

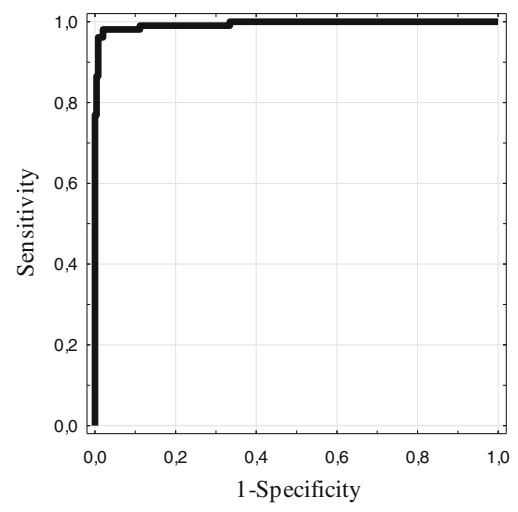

ROMA P, advanced ovarian cancer

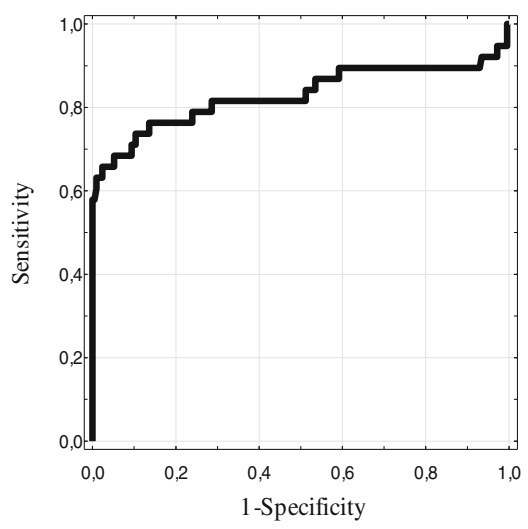

ROMA P, premenopausal women

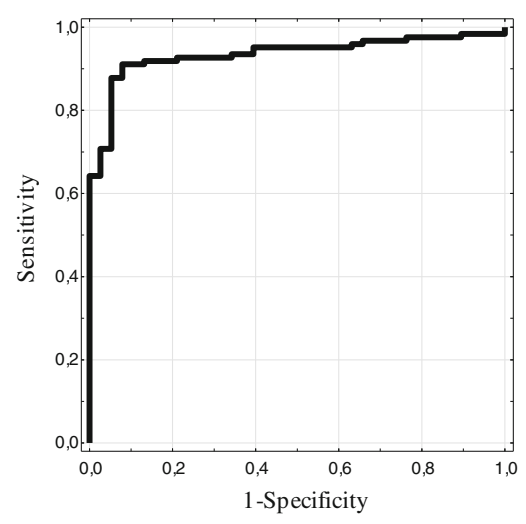

ROMA P, postmenopausal women 
Table 4 Values and comparisons of ROCAUC for ROMA, ROMA P, CA125, and HE4 in studied interval age

\begin{tabular}{|c|c|c|c|c|c|}
\hline \multirow{2}{*}{$\begin{array}{l}\text { Age } \\
\text { interval }\end{array}$} & \multirow{2}{*}{$\begin{array}{l}\text { Tumor } \\
\text { marker }\end{array}$} & \multirow{2}{*}{$\begin{array}{l}\text { ROC-AUC } \\
(95 \% \text { CI })\end{array}$} & \multicolumn{3}{|c|}{ Comparison of ROC-AUC } \\
\hline & & & $\begin{array}{l}\text { ROMA P vs. CA } 125 \\
p \text { value }\end{array}$ & $\begin{array}{l}\text { ROMA P vs. HE4 } \\
p \text { value }\end{array}$ & $\begin{array}{l}\text { ROMA P vs. ROMA } \\
p \text { value }\end{array}$ \\
\hline \multirow[t]{4}{*}{ W2 } & ROMA & 0.755 & \multirow[t]{4}{*}{0.3862} & \multirow[t]{4}{*}{0.7901} & \multirow[t]{4}{*}{0.6745} \\
\hline & ROMA P & 0.745 & & & \\
\hline & HE4 & 0.739 & & & \\
\hline & CA125 & 0.673 & & & \\
\hline \multirow[t]{4}{*}{ W3 } & ROMA & 0.675 & \multirow[t]{4}{*}{0.0946} & \multirow[t]{4}{*}{0.2646} & \multirow[t]{4}{*}{0.2545} \\
\hline & ROMA P & 0.703 & & & \\
\hline & HE4 & 0.669 & & & \\
\hline & CA125 & 0.982 & & & \\
\hline \multirow[t]{4}{*}{ W4 } & ROMA & 0.863 & \multirow[t]{4}{*}{0.9539} & \multirow[t]{4}{*}{0.0673} & \multirow[t]{4}{*}{0.6745} \\
\hline & ROMA P & 0.872 & & & \\
\hline & HE4 & 0.826 & & & \\
\hline & CA125 & 0.868 & & & \\
\hline \multirow[t]{4}{*}{ W5 } & ROMA & 0.955 & \multirow[t]{4}{*}{0.3405} & \multirow[t]{4}{*}{0.0321} & \multirow[t]{4}{*}{0.069} \\
\hline & ROMA P & 0.926 & & & \\
\hline & HE4 & 0.864 & & & \\
\hline & CA125 & 0.956 & & & \\
\hline \multirow[t]{4}{*}{ W6 } & ROMA & 0.908 & \multirow[t]{4}{*}{0.3528} & \multirow[t]{4}{*}{0.1221} & \multirow[t]{4}{*}{0.1468} \\
\hline & ROMA P & 0.895 & & & \\
\hline & HE4 & 0.869 & & & \\
\hline & CA125 & 0.923 & & & \\
\hline \multirow[t]{4}{*}{ W7 } & ROMA & 0.96 & \multirow[t]{4}{*}{0.3472} & \multirow[t]{4}{*}{0.3881} & \multirow[t]{4}{*}{1} \\
\hline & ROMA P & 0.96 & & & \\
\hline & HE4 & 0.93 & & & \\
\hline & CA125 & 0.9 & & & \\
\hline
\end{tabular}

age groups and differentiation of modification and directional coefficients in the ROMA algorithm calculation formula. AUC values determined for the modified algorithm ROMA P meet the criteria of a very good diagnostic test in every analysis (all ovarian cancer patients: $\mathrm{AUC}=0.923$; advanced ovarian cancer patients: $\mathrm{AUC}=0.994$; early-stage ovarian cancer patients: $\mathrm{AUC}=0.794$; premenopausal women: $\mathrm{AUC}=0.829$; and postmenopausal women: $\mathrm{AUC}=0.935)$. No significant differences were observed when comparing AUC values between the standard and the modified method of algorithm calculation. However, clinically significant differences were observed when comparing specificity, PPV, and NPV. ROMA algorithm calculated according to the standard formula was characterized by better sensitivity and positive prediction values. However, the ageadjusted algorithm ROMA P proved significantly superior in terms of sensitivity and negative predictive values with only a minor reduction in sensitivity in premenopausal women only. The results in premenopausal women were as follows: sensitivity $64.9 \%$, specificity $99.1 \%$, PPV $92.3 \%$, and NPV 94.2. Results in postmenopausal women were 91.1, 91.9, 97.4, and $75.6 \%$, respectively. Compared with the results obtained by other authors who analyzed the ROMA algorithm using the standard criteria, the obtained results are very good. In their studies, Moore et al. [24] obtained the sensitivity of $88.1 \%$, specificity of $74.2 \%$, PPV of $17.8 \%$, and NPV of 98.3 NPV in premenopausal women compared with $90.2,76,56.1$, and $95.8 \%$ in postmenopausal

Table 5 Sensitivity, specificity, PPV, and NPV of ROMA and ROMA P

\begin{tabular}{|c|c|c|c|c|c|c|c|c|c|c|c|c|}
\hline \multirow[t]{2}{*}{ Ovarian cancer vs. benign ovarian diseases } & \multicolumn{3}{|c|}{ Sensitivity $(\%)$} & \multicolumn{3}{|c|}{ Specificity $(\%)$} & \multicolumn{3}{|c|}{ PPV (\%) } & \multicolumn{3}{|c|}{ NPV(\%) } \\
\hline & All & PM & M & All & PM & M & All & PM & M & All & PM & M \\
\hline ROMA & 88.1 & 75.7 & 91.9 & 84.9 & 92.5 & 89.2 & 87.6 & 63.6 & 96.6 & 92.4 & 95.7 & 76.7 \\
\hline ROMA P & 85 & 64.9 & 91.1 & 98 & 99.1 & 91.9 & 96.5 & 92.3 & 97.4 & 84.8 & 94.2 & 75.6 \\
\hline
\end{tabular}


women, respectively. Molina et al. [27] obtained analogous results in premenopausal women: $74.1,88.9,44.4$, and $96.6 \%$ as well as in postmenopausal women: $95.2,83.1,88.9$, and $92.5 \%$.

To date, the only paper that included stratification of patients on the basis of HE4, CA125, and patient age was published several months ago [34]. It relates to a large, multicenter study in which 2665 at 8 centers were analyzed on the basis of the Copenhagen Index (CPH-I). Assuming that the cutoff value for CPH-I is at the level of 0.07 , sensitivity and specificity values of 95 and $78.4 \%$ were obtained, respectively.

\section{Conclusion}

It appears that further studies on the improvement of diagnostic criteria of CA125- and HE4-based algorithm consisting in elimination of the impact of factors potentially affecting the values of both markers and thus of the algorithm itself, is a legitimate trend. As shown by the results of our analysis, the proposed age-related modification of algorithm calculation does not require the patients being dichotomized according to their pre- or postmenopausal status and satisfactory diagnostic values may be obtained using a single cutoff point for the entire population.

Acknowledgments Thanks to the staff of the Central Laboratory SPSK No. 2 Pomeranian Medical University in Szczecin for carrying out the assays of tumor markers.

\section{Compliance with ethical standards}

Conflicts of interest None

Open Access This article is distributed under the terms of the Creative Commons Attribution 4.0 International License (http:// creativecommons.org/licenses/by/4.0/), which permits unrestricted use, distribution, and reproduction in any medium, provided you give appropriate credit to the original author(s) and the source, provide a link to the Creative Commons license, and indicate if changes were made.

\section{References}

1. Ferlay J, Soerjomataram I, Ervik M, Dikshit R, Eser S, Mathers C et al. Globocan 2012 v 1.0, Cancer Incidence and Mortality Worldwide: IARC Cancer Base No. 11. Lyon, France: International Agency for Research on Cancer; 2013. Available from: http://globcan.iarc.fr. Accessed on 20 Jul 2014.

2. Nelson HD, Fu R, Goddard K, Mitchell JP, Okinaka-Hu L, Pappas $\mathrm{M}$, et al. Risk assessment, genetic counseling, and genetic testing for BRCA-related cancer: systematic review to update the U.S. Preventive Services Task Force. Rockville: Recommendation Agency for Healthcare Research and Quality (US); 2013.

3. De Angelis R, Sant M, Coleman MP, Francisci S, Baili P, Pierannunzio D, et al. Cancer survival in Europe, 1999-2007 by country and age: results of EUROCARE- 5 a population based study. Lancet Oncol. 2014;15:23-34.
4. Bast Jr RC, Klug TL, St John E, Jenison E, Niloff JM, Lazarus H, et al. A radioimmunoassay using a monoclonal antibody to monitor the course of epithelial ovarian cancer. N Engl J Med. 1983;309:169-71.

5. Hellström I, Raycraft J, Hayden-Ledbetter M, Ledbetter JA, Schummer M, Mcintosh M, et al. The HE4 (WFDC2) protein is a biomarker for ovarian carcinoma. Cancer Res. 2003;63:3695-700.

6. Bandiera E, Romani C, Specchla C, Zanotti L, Galli C, Ruggieri G, et al. Serum human epididymis protein 4 and risk for ovarian malignancy algorithm as new diagnostic and prognostic tools for epithelial ovarian management. Cancer Epidemiol Biomarkers Prev. 2011;20:2496-506.

7. Ławicki S, Będkowska EG, Gacuta-Szumarska E, Szmitkowski M. The plasma concentration of VEGF, HE4 and CA 125 as new biomarkers panel in different stages and subtypes of epithelial ovarian tumors. J Ovarian Res. 2013;6:45.

8. Hellstrom I, Hellstrom KE. Two novel biomarkers, mesothelin and HE4, for diagnosis of ovarian carcinoma. Expert Opin Med Diagn. 2011;5:227-40.

9. Drapkin R, von Horsten HH, Lin Y, Mok SC, Crum CP, Welch WR, et al. Human epididymis protein 4 (HE4) is a secreted glycoprotein that is overexpressed by serous and endometrioid ovarian carcinomas. Cancer Res. 2005;65:2162-9.

10. Kadija S, Stefanovic A, Jeremic K, Radojevic MM, Nikolic L, Markovic I, et al. The utility of human epididymal protein 4, cancer antigen 125, and risk form malignancy algorithm in ovarian cancer and endometriosis. Int J Gynecol Cancer. 2012;22:238-44.

11. Langmár Z, Németh M, Vleskó G, Király M, Hornyák L, Bosze P. HE4- a novel promising serum marker in the diagnosis of ovarian carcinoma. Eur J Gynaecol Oncol. 2011;32:605-10.

12. Moore RG, Brown AK, Miller MC, Skates S, Allard WJ, Verch T, et al. The use of multiple novel tumor biomarkers for the detection of ovarian carcinoma in patients with a pelvic mass. Gynecol Oncol. 2008;108:402-8.

13. Montagnana M, Danese E, Ruzzenente O, Bresciani V, Nuzzo T, Gelati M, et al. The ROMA (risk of ovarian malignancy algorithm) for estimating the risk of epithelial ovarian cancer in women presenting with pelvic mass: is it really useful? Clin Chem Lab Med. 2011;49:521-5.

14. Moore RG, Jabre-Raughley M, Brown AK, Robison KM, Miller $\mathrm{MC}$, Allard WJ, et al. Comparison of a novel multiple marker assay vs the Risk of Malignancy Index for the prediction of epithelial ovarian cancer in patients with a pelvic mass. Am J Obstet Gynecol. 2010;203:e1-6.

15. Ortiz-Munoz B, Aznar-Oroval E, Garcia AG, Peris AC, Ballestero PP, Yepes MS, et al. HE4, CA 125 and ROMA algorithm for differential diagnosis between benign gynaecological diseases and ovarian cancer. Tumor Biol. 2014;35:7249-58.

16. Lenhardt M, Stieber P, Hertlein L, Kirschenhofer A, Furst S, Mayr $\mathrm{D}$, et al. The diagnostic accuracy of two epididymis protein 4 (HE4) testing system in combination with CA 125 in the differential diagnosis of ovarian masses. Clin Chem Lab Med. 2011;49:2081-8.

17. Plebani M. HE4 in gynecological cancers: report of a European investigators and experts. Clin Chem Lab Med. 2012;50:2127-36.

18. Plebani M, Melichar B. ROMA or death: advances in epithelial ovarian cancer diagnosis. Clin Chem Lab Med. 2011;49:433-5.

19. Park Y, Lee JH, Hong DJ, Lee EY, Kim HS. Diagnostic performance of HE4 and CA125 for the detection of ovarian cancer from patients with various gynecologic and non-gynecologic diseases. Clin Biochem. 2011;44:884-8.

20. Azzam AZ, Hashad DI, Kamel N. Evaluation of HE4 as an extra biomarker to CA 125 to improve detection of ovarian carcinoma: is it time for step forward. Arch Gynecol Obstet. 2013;288:167-72.

21. Andersen MR, Goff BA, Kimberly AL, Scholler N, Bergan L, Drescher C, et al. Use of a symptom index, CA 125 and HE4 to predict ovarian cancer. Gynecol Oncol. 2010;116:378-83. 
22. Ferraro S, Bragna F, Lanzoni M, Boracchi P, Bignazoli EM, Panteghini M. Serum human epididymis protein 4 vs carbohydrate antigen CA 125 for ovarian cancer diagnosis. J Clin Pathol. 2013;66:273-81.

23. Moore RG, McMeekin DS, Brown AK, DiSilvestro P, Miller MC, Allard WJ, et al. A novel multiple marker bioassay utilizing HE4 and CA125 for the prediction of ovarian cancer in patients with a pelvic mass. Gynecol Oncol. 2009;112:40-6.

24. Moore RG, Miller MC, Disilvestro P, Landrum LM, Gajewski W, Ball JJ, et al. Evaluation of the diagnostic accuracy of the risk of ovarian malignancy algorithm in women with a pelvic mass. Obstet Gynecol. 2011;118:280-8.

25. Kalapotharakos G, Asciutto C, Henic B, Casslen B, Borgfeldt C. High preoperative blood levels of HE4 predicts poor prognosis in patients with ovarian cancer. J Ovarian Res. 2012;5:20.

26. Ruggeri G, Bandiera E, Zanotti L, Belloli S, Ravaggi A, Romani C, et al. HE4 and epithelial ovarian cancer: comparison and clinical evaluation of two immunoassays and a combination algorithm. Clin Chim Acta. 2011;412:1447-53.

27. Molina R, Escudero JM, Auge JM, Filella X, Foj L, Torne A, et al. Her novel tumor marker for ovarian cancer: comparison with CA 125 and ROMA algorithm in patients with gynaecological diseases. Tumor Biol. 2011;32:1087-95.

28. Sandri MT, Bottari F, Franchi D, Boveri S, Candiani M, Ronzoni S, et al. Comparison of HE4, CA125 and ROMA algorithm in women with a pelvic mass: correlation with pathological outcome. Gynecol Oncol. 2013;128:233-8.

29. Karlsen MA, Sandhu N, Hodgall C, Christensen IJ, Nedergaad L, Lundvall L, et al. Evaluation of HE4, CA 125, risk of malignancy algorithm (ROMA) and risk of malignancy index (RMI) as diagnostic tools of epithelial ovarian cancer patients with pelvic mass. Gynecol Oncol. 2012;127:379-83.

30. Lowe K, Shah C, Wallace E, Anderson G, Paley P, McIntosh M, et al. Effects of personal characteristics on serum CA125, mesothelin, and HE4 levels in healthy postmenopausal women at high risk for ovarian cancer. Cancer Epidemiol Biomarkers Prev. 2008;17:2480-7.

31. Moore RG, Miller MC, Eklund EE, Lu KH, Bast Jr RC, LamberMesserlian G. Serum levels of the ovarian cancer biomarker HE4 are decreased in pregnancy and increase with age. Am J Obstet Gynecol. 2012;206:349E1-7.

32. Bolstad N, Oijordsbakken M, Neustad K, Bjerner J. Human epididymis protein 4 reference limits and natural variation in a Nordic reference population. Tumor Biol. 2012;33:141-8.

33. Park Y, Kim Y, Lee EY, Lee J, Kim H. Reference ranges for HE4 and CA125 in a large Asian population by automated assays and diagnostic performances for ovarian cancer. Int J Cancer. 2012;130:1136-44.

34. Karlsen MA, Hogdall EV, Christensen IJ, Borgfeldt C, Kalapotharakos G, Zdrazilova-Dubska L, et al. A novel diagnostic index combining HE4, CA 125 and age may improve triage of women with suspected ovarian cancer - an international multicenter study in women with ovarian mass. Gynecol Oncol. 2015;138:640-6. 